\section{1,230 CASES OF ACUTE BRONCHIOLITIS IN INFANCY}

\author{
BY
}

\section{J. B. HEYCOCK, M.C., T.D., M.R.C.P., D.C.H. Senior Consultant Paediatrician \\ AND}

\author{
T. C. NOBLE, M.B., M.R.C.P.Ed., D.C.H. \\ Consultant Paediatrician
}

From the Sunderland Children's Hospital

Six years ago we described a single epidemic of acute bronchiolitis involving 164 infants (Heycock and Noble, 1956). Since then 1,230 cases of this disease have been treated in Sunderland Children's Hospital, and we think it is of interest to analyse their case records and to consider theories of aetiology and treatment on the basis of this experience. We define acute bronchiolitis as a potentially serious infective illness of infancy which involves the whole respiratory tract and in which bronchospasm plays a large part.

\section{Clinical Description}

The baby acquires a cold from an older child or adult, usually in the family. The baby itself develops a nasal discharge and slight cough with anorexia. This clinical picture may remain unchanged for a few days before clearing up or there may be a rapid increase in the severity of the symptoms. In the more severely affected patients acute respiratory distress, including frequent irritating unproductive cough and bronchospasm, can develop within a few hours. An expiratory wheeze is present with rib recession, rapid heart rate and respirations, and sometimes cyanosis. Froth may appear on the lips and in some cases there is restlessness due to hypoxia.

On auscultation of the lungs the outstanding features are generalized rhonchi with poor air entry, and often crepitations over the lower lobes at some stage in the illness. Slight splenomegaly is a frequent finding. In the most severe cases signs of heart failure are superimposed, and the liver becomes enlarged. A surprising feature in this condition is the absence, or brief duration, of fever.

Most infants remain distressed for two or three days and then improve steadily, returning to normal health at the end of a week or ten days, though slight cough and wheeze may persist for two weeks or longer. The first signs of recovery are improvement in colour, disappearance of restlessness, and return of appetite.

\section{Treatment}

A large proportion of babies with acute bronchiolitis can be treated safely at home. The infant is best nursed in a cot and handled as little as possible apart from feeding. It must be emphasized to the parents that the baby must not be over-covered or nursed in constricting clothing, and that the room should be cool and well ventilated to avoid hyperpyrexia. Glucose-saline feeds (1 pint $(570 \mathrm{ml}$.) boiled water, 4 teaspoonfuls sugar, $\frac{1}{4}$ teaspoonful salt) are given for the first day or two until appetite returns ; this reduces the risk of abdominal distension and inhalation of vomit.
Tetracycline is given in doses of $12 \mathrm{mg} . / \mathrm{lb}$. $(30 \mathrm{mg} . /$ kg.) bodyweight per day in four divided doses (sixhourly) for five or six days, and the more severely affected baby probably benefits from an initial dose of 500,000 units of penicillin by intramuscular injection.

At the end of a week the majority of infants will have recovered, but a few are left with some cough and bronchospasm, which can persist for another week. In these cases a further five-day course of oral penicillin or sulphadimidine often helps.

If, in spite of this treatment, any of the following signs or symptoms appear the baby should be admitted to hospital: (1) persistent cyanosis, (2) increasing restlessness, (3) persistent tachycardia, (4) complete refusal to take feeds, even of glucose saline, or (5) any type of convulsion.

In hospital the same antibiotic treatment is continued and the infant may be nursed in an oxygen tent until signs and symptoms of hypoxia disappear. Adrenal steroids can be tried in the few cases not responding to routine hospital measures. Digitalis is reserved for cases showing definite signs of heart failure.

\section{Analysis of Case Records \\ Incidence and Mortality}

In this area there is an epidemic of bronchiolitis each winter lasting for two or three months, during which time $70 \%$ of the annual total cases of this condition are admitted, Table I). There is usually an epidemic of common cold in the adult population at the same time. Sporadic cases occur throughout the rest of the year. In five of the eight years under consideration the epidemics occurred in the three-month period of November, December, and January, and in the other three years the peaks were in January, February, and March.

The overall mortality rate in this series (Table II) is $5.5 \%$, which might seem high in relation to the figures published by Morrison (1955) and Disney (1960), but included in our figures are 27 patients who died within six hours of admission and 19 cases with potentially dangerous congenital abnormalities such as mongolism, severe congenital heart disease, and spina bifida. These cases represent two-thirds of the total deaths. The sex and birth weights of the infants appeared to be of no significance in relation to incidence or mortality.

\begin{tabular}{|c|c|c|c|}
\hline Year & Total Cases & $\begin{array}{l}\text { Cases Admitted } \\
\text { in } \\
\text { Peak Trimester }\end{array}$ & Deaths \\
\hline $\begin{array}{l}1954 \\
1955 \\
1956 \\
1957 \\
1958 \\
1959 \\
1960 \\
1961\end{array}$ & $\begin{array}{l}125 \\
135 \\
100 \\
290 \\
109 \\
132 \\
179 \\
160\end{array}$ & $\begin{array}{r}84 \\
113 \\
69 \\
200 \\
72 \\
84 \\
103 \\
106\end{array}$ & $\begin{array}{r}9 \\
10 \\
8 \\
4 \\
8 \\
8 \\
8 \\
13\end{array}$ \\
\hline Totals & 1,230 & 831 & 68 \\
\hline
\end{tabular}

TABLE II.-Mortality and Incidence in Relation to Age

\begin{tabular}{cc|c|c|c}
\hline Age & & $\begin{array}{c}\text { Birth to } \\
6 \text { Months }\end{array}$ & $\begin{array}{c}7 \text { Months to } \\
1 \text { Year }\end{array}$ & $\begin{array}{c}\text { 1 Year to } \\
\text { 2 Years }\end{array}$ \\
\hline $\begin{array}{cc}\text { Total cases } \\
\text { No. of deaths }\end{array}$ & $\ldots$ & 890 & 207 & 133 \\
\hline$\%$ mortality & $\ldots$ & 59 & 4 & 5 \\
\hline
\end{tabular}


Symptoms had been present in 779 babies for three days or less before admission, while 451 had been unwell for four or more days. Of the total of 1,230 cases, 1,042 could be discharged home in ten days or less: $188 \mathrm{had}$ to be kept in hospital for 11 days or more. We found this information useful during epidemic periods in estimating the adequacy of infant accommodation in the area.

\section{Treatment and Complications}

Relapses or second attacks occurred in 78 patients $(6.2 \%)$, who were readmitted at intervals varying from two weeks to one year after their original attacks. No child suffered more than two severe attacks.

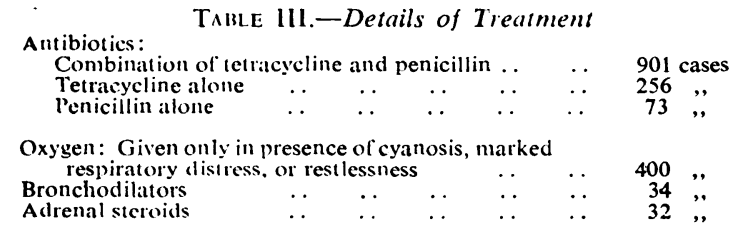

Complications.-These were relatively infrequent. Some bronchospasm tended to persist for two to three weeks after acute bronchiolitis in many babies. A few were troubled by mild wheezy bronchitis in the first few months after discharge, but thereafter these patients were no more liable to wheezy bronchitis or asthma than is the general infant population of this area. No cases of permanent lung damage have been found. In only 25 babies did convulsions occur at the onset of the illness and there was significant diarrhoea in 21 .

$X$-rays. - The majority showed only bilateral basal emphysema and increase of lung markings, but localized areas of collapse were present (Table IV).

\begin{tabular}{c|c|c|c}
\multicolumn{3}{c}{ TABLE IV.--Radiological Collapse } \\
\hline $\begin{array}{c}\text { Total Cases with } \\
\text { Localized Collapse }\end{array}$ & $\begin{array}{c}\text { Right } \\
\text { Lung }\end{array}$ & $\begin{array}{c}\text { Left } \\
\text { Lung }\end{array}$ & Bilateral \\
\hline 188 & 103 & 42 & 43 \\
\hline
\end{tabular}

Temperature.-No rise of temperature occurred in 355 babies; 789 had rectal temperatures above $99^{\circ} \mathrm{F}$. $\left(37.2^{\circ}\right.$ C.) for one to three days, and only 86 had fever for four or more days.

\section{Discussion}

Our experience of this disease has led us to believe that bronchiolitis in infancy begins as a virus infection of the upper respiratory tract. This assumption is based on the presence of common colds among the patient's family and, conversely, the occurrence of common colds among older children exposed in hospital wards to babies with bronchiolitis. Since it seems probable that different viruses are involved in the production of common colds, it is illogical to expect one virus to be responsible for all cases of acute bronchiolitis.

In the infant the virus gains access to the upper respiratory tract, causing symptoms and signs of common cold, and may spread down to involve the lower bronchial tree, resulting in acute bronchiolitis. The signs of involvement of the smaller bronchi, bronchioles, and alveoli can vary greatly from rhonchi to crepitations during the course of the illness, depending on whether obstruction or exudate is predominant. We feel that acute bronchiolitis is the commonest picture of acute infection of the lower respiratory tract in infancy and that it is incorrect to make a clear-cut distinction between bronchiolitis and bronchopneumonia.

The mortality in this series has been highest in the youngest infants, and we think that this is related to the relatively greater degree of obstruction produced by exudate in small-calibre bronchi. In the toddler agegroup the same infection often produces nothing more than wheezy bronchitis which also reaches its peak incidence at the time of the bronchiolitis epidemics.

Although we consider that the initial infection is caused by the viruses of the common cold, we believe that secondary bacterial infection is almost inevitable, probably as a result of commensal organisms from the upper respiratory tract gaining access to an already inflamed mucous membrane (McKerrow, 1961). A number of these cases had radiological abnormalities very suggestive of a staphylococcal pneumonia, and we think that those, also, started as typical bronchiolitis. It seems possible that this dual mechanism of infection might apply to the other infections of the lower respiratory tract of all age-groups. We wonder whether this same mechanism might even operate in a septicaemic illness such as meningococcal infection whose incidence increases in this area during the epidemic periods of acute bronchiolitis. Therefore we recommend broadspeatrum antibiotics in all cases of bronchiolitis and even for the treatment of common colds in very young babies during epidemic periods.

With regard to treatment our routine is to put babies showing cyanosis or restlessness in a standard oxygen tent with a flow of 6-8 litres per minute. Although Morrison (1955) suggests that the oxygen concentration in an ordinary tent is inadequate in relieving the restlessness of some of these babies, we have found it sufficient to tide them over the period of acute hypoxia. The deaths which have occurred were in those showing signs suggestive of heart failure rather than extreme respiratory distress. All babies are given antibiotics, the great majority receiving tetracycline with or without injections of penicillin for about seven days. Feeds of glucosesaline are offered in the initial stages, and milk is given to most within 48 hours. Adrenal steroids have been given in 32 cases, all desperately ill, in an effort to reduce bronchospasm. Given as intramuscular hydrocortisone in a three-day course, with $100 \mathrm{mg}$. in the first 24 hours, they seemed to be effective in some cases, though 13 infants died in spite of this treatment. We find other bronchodilator drugs to be of no use in the acute stages, though they sometimes relieve the mild spasm in the second week. We have no experience of bronchoscopic toilet, but would hesitate to use this method in ill babies, the majority of whom respond to the treatment mentioned.

We have not encountered any permanent lung damage as a result of bronchiolitis. While we previously suggested (Heycock and Noble, 1956) that a higher proportion of these infants seemed liable to wheezy bronchitis we now think that this tendency lasts, at the most, for a year after the initial illness, and there seems to be no increased liability to bronchospasm in later childhood.

This plan of treatment has resulted in a mortality of $5 \%$, one-third of these patients dying within six hours of admission and over a quarter having a serious congenital abnormality. 


\section{Summary}

A survey has been made of 1,230 cases of acute bronchiolitis of infancy occurring in a children s hospital over an eight-year period.

It is postulated that bronchiolitis is an acute infection of the whole respiratory tract in babies, caused by the viruses of the common cold, and that secondary infection of some degree is almost inevitable. It is suggested that this dual mechanism of infection applies in other illnesses and other age groups.

The clinical features consist of signs of infection of the upper respiratory tract followed by persistent cough and marked bronchospasm. There are often crepitations at the lung bases and there may be cyanosis and restlessness. The signs vary with the stage of the illness, and it is suggested that acute bronchiolitis cannot be separated clinically from bronchopneumonia in infancy. The acute phase of bronchiolitis seldom lasts for more than a week, but cough and wheeze can persist for another fortnight.

The suggested plan of treatment emphasizes the need for broad-spectrum antibiotics in all cases. Some babies can be treated at home, and one of the main indications for admission to hospital is the need for oxygen therapy.

The mortality during the period under discussion has been $5.5 \%$. This includes many babies with serious congenital abnormalities. Three out of four babies admitted with bronchiolitis are under 6 months of age, and the death rate is highest in this age group. There is no significant morbidity in infants who recover, and second attacks are rare.

Tables giving details of age, mortality, radiological findings, and treatment are presented.

We wish to record our appreciation of the work done by the medical and nursing staffs of this hospital in the management of these sick babies, and we wish to thank Miss B. D. Stuart for her secretarial assistance.

\section{REFERENCES}

Disney, M. E., Sandiford, B. R., Cragg, J., and Wolff, J. (1960). Brit. med. J., 1. 1407

Heycock, J. B., and Noble, T. C. (1956). Ibid., 1, 438.

McKerrow, C. B., Oldham, P. D., and Thomson, S. (1961) Lancet, 1, 185

Morrison, B. (1955). Ibid., 2, 737.

\title{
RESPIRATORY SYNCYTIAL VIRUS IN EPIDEMIC BRONCHIOLITIS OF INFANTS
}

BY

\author{
B. R. SANDIFORD, M.D. B. SPENCER, F.I.M.L.T. \\ Public Health Laboratory, Birmingham
}

During the winter of 1956-7 an investigation into epidemic bronchiolitis of infants in Birmingham was carried out (Disney et al., 1960). In the course of it throat swabs, stools, and aspirated lung juices were collected from 73 infants. These were examined by culture in chick embryos, HeLa cells, human amnion cells, and monkey-kidney cells for evidence of a causative virus. Acute and convalescent sera were also examined by the complement-fixation test (C.F.T.) for antibody to influenza, parainfluenza, adeno, $Q$ fever, and psittacosis-lymphogranuloma venereum viruses. No evidence for a causative virus was found (Sandiford, 1960).

After storage for five years at $-30^{\circ} \mathrm{C}$. some of the sera have been reinvestigated for complement-fixing antibody to respiratory syncytial virus (R.S.V.), which was unknown as a human pathogen at the time of the original investigation.

\section{Materials and Methods Used}

The antigen was prepared from the Randall strain of R.S.V. grown on a monocellular layer of R.S.V.-sensitive HeLa cells in a "medical flat" until there was a marked cytopathic effect. The bottle's contents were then frozen and thawed thrice and suspended debris was centrifuged out. The supernatant fluid was titrated, "chessboard" fashion, against rabbit R.S.V. antiserum supplied by Dr. S. Clarke, of Bristol Public Health Laboratory. The optimum dilution of antigen proved to be 1 in 2 , and this dilution was used in the C.F.T.s which were carried out in "perspex" plates by overnight fixation at $4^{\circ} \mathrm{C}$.

Screening tests on the convalescent sera at a dilution of 1 in 8 were first put up. In cases which showed at least a 2-plus reaction both acute and convalescent sera were then titrated, starting at a 1 in 2 dilution with the former and at 1 in 8 with the latter.

\section{Results}

Thirty-two pairs of sera were available for testing, of which seven were eliminated by the screening test. Of the 25 pairs which were then titrated, 22 showed a fourfold or greater rise in complement-fixing antibodies between individual members of a pair (see Table).

Complement-fixation Tests for Respiratory Syncytial Virus on Infants' Sera

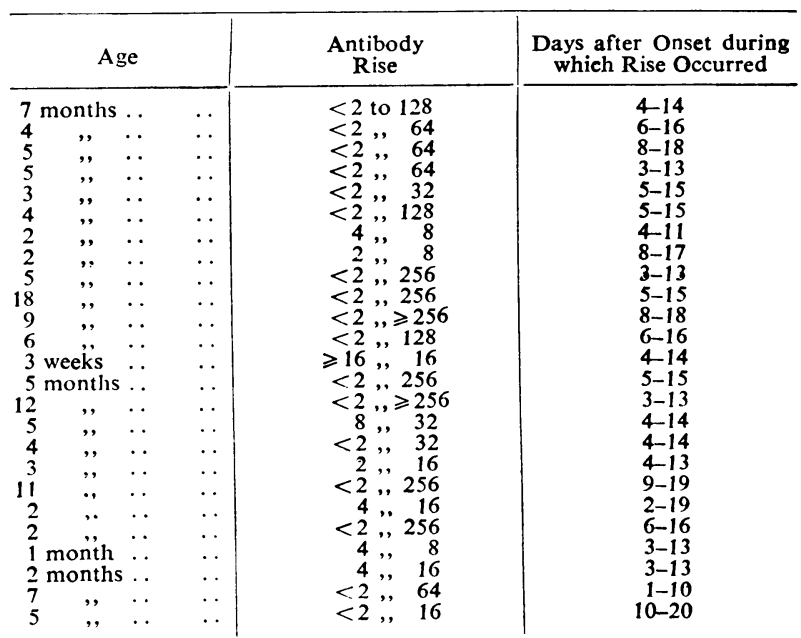

Results are recorded as reciprocals of the reacting titres. $\geqslant$ Means equa to or greater than the recorded titre. 